\title{
Lymphocytic Esophagitis: A Rare Disease on the Rise
}

\author{
Lindsey C. Shipley ${ }^{1}$, Laith A. Al Momani ${ }^{2}$, Allison Locke ${ }^{3}$, Mark Young ${ }^{4}$ \\ 1. Internal Medicine, Quillen College of Medicine, East Tennessee State University 2. Internal Medicine, \\ East Tennessee State University 3. ETSU Gastroenterology, East Tennessee State University 4. \\ Gastroenterology Associates of Northeast Tennessee, East Tennessee State University
}

$\square$ Corresponding author: Lindsey C. Shipley, crosnoe@goldmail.etsu.edu Disclosures can be found in Additional Information at the end of the article

\section{Abstract}

Lymphocytic esophagitis is a rare, poorly understood disease. This case report presents a patient with a history of squamous cell carcinoma of the tongue who presented with dysphagia. He received esophageal dilation that unfortunately resulted in perforation. Biopsies showed lymphocytic esophagitis. There are very few cases in the literature describing perforation in lymphocytic esophagitis. In addition, management and treatment have been challenging for physicians; however, this case represents a complete symptomatic improvement in four to six weeks with a proton pump inhibitor.

Categories: Internal Medicine, Gastroenterology

Keywords: esophagitis, lymphocytic esophagitis, perforation

\section{Introduction}

Lymphocytic esophagitis (LE) is a rare disorder of the esophagus with most cases presenting with normal-appearing esophageal mucosa [1-2]. This case report discusses a patient with a history of post-radiation squamous cell carcinoma of the tongue, who presented with dysphagia due to recurrent esophageal strictures. Dilation, unfortunately, resulted in perforation.

\section{Case Presentation}

A 71-year-old male patient, with a known history of squamous cell carcinoma of the tongue treated with external beam radiation 17 years prior, presented to the clinic for esophagogastroduodenoscopy (EGD) with dilation for a follow-up for esophageal strictures. His only complaint at this time was dysphagia.

Received 01/12/2018

Review began 01/25/2018 Review ended 02/01/2018 Published 02/04/2018

\section{(c) Copyright 2018}

Shipley et al. This is an open access article distributed under the terms of the Creative Commons Attribution License CC-BY 3.0., which permits unrestricted use, distribution, and reproduction in any medium, provided the original author and source are credited.
On prior EGD, he was noted to have a stricture in the upper esophagus, a ringed lower esophagus, and a lower esophageal stricture. His past medical history was significant for squamous cell carcinoma of the tongue status post radiation, gastroesophageal reflux disorder, and hypertension. Surgical history consisted of multiple EGDs requiring dilation with a French Maloney. A physical examination revealed no abnormal findings and laboratory testing was unremarkable.

The patient underwent the procedure with dilation, at which time a characteristic white streaking and esophageal stricture were noted, as seen in Figure 1. However, this procedure was unfortunately complicated by an esophageal tear requiring six endoclips to close. The patient 


\section{Cureus}

was admitted for observation, treated conservatively, and discharged the following day after a negative gastrografin esophagram. Biopsies were taken at the time of the procedure,

which showed lymphocytic esophagitis with greater than 45 lymphocytes per high power field. This patient was treated with four-week proton pump inhibitor (PPI) therapy that resulted in complete symptom resolution.

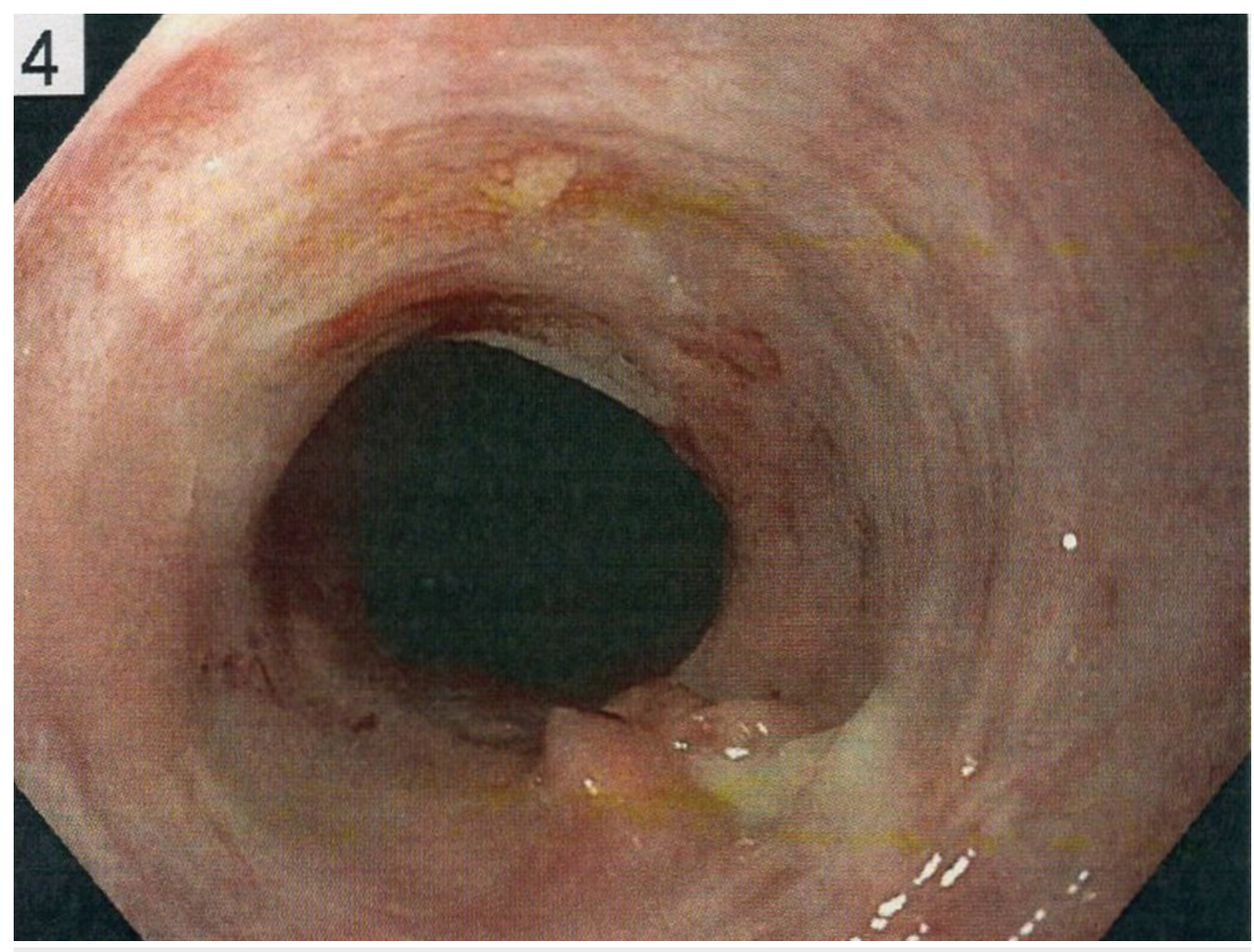

FIGURE 1: White streaking and stricture of esophagus via esophagogastroduodenoscopy

\section{Discussion}

Current treatment recommendations for lymphocytic esophagitis include symptomatic management similar to that in eosinophilic esophagitis or gastroesophageal reflux disease (GERD). However, there are no guidelines for the safety of endoscopic procedures in these cases. Combining both biopsy and dilation can increase the risk for perforation. We suggest delaying endoscopic dilation in such patients until symptoms have either resolved or improved.

Lymphocytic esophagitis (LE) is a rare disorder of the esophagus that was first reported in 2006 [3]. In a demographic study by Genta et al., only 116 patients were identified out of 129,252 [4]. The rise in the diagnosis of lymphocytic esophagitis could be due to the increase in endoscopic procedures and the availability of dedicated pathologists. LE is characterized by an increased number of intraepithelial lymphocytes without granulocytosis in the esophagus [5]. It appears to have a benign course in most patients and is most commonly found in older females and in younger patients with inflammatory bowel disease, specifically Crohn's Disease. The most frequent endoscopic findings include esophageal rings, esophagitis, and esophageal strictures. Perforation is an uncommon complication of lymphocytic esophagitis and has only been documented in two other cases in the literature [2]. 
Intraepithelial lymphocytes in the esophagus are relatively common and the differential is broad, to include gastroesophageal reflux, lymphocytic esophagitis, changes associated with radiation therapy, and mucosal changes in motility disorders [2]. Diagnosis includes a biopsy with a high number of intraepithelial lymphocytes in the peripapillary areas (more than 35 lymphocytes per high power field) in addition to the absence of both eosinophils and granulocytes and severe spongiosis [5].

The management and treatment of symptomatic lymphocytic esophagitis are challenging for physicians, as there are no formal guidelines. Current treatment recommendations include symptomatic management similar to that in eosinophilic esophagitis or GERD, which includes proton pump inhibitors, swallowed topical steroids, and endoscopic dilation [3]. In addition, special precautions should be taken when performing endoscopic dilation, as a few cases have resulted in perforation [2].

\section{Conclusions}

This case highlights a rare complication of lymphocytic esophagitis. We aim to make providers aware that these patients may be at greater risk for esophageal perforation. If lymphocytic esophagitis is suspected by endoscopy, and both biopsy and dilation are required, it may be in the patient's best interest to wait for dilation until they have received four to six weeks of proton pump inhibitors, to decrease the risk of perforation. However, more research is needed to determine the best approach for the management of patients with LE.

\section{Additional Information \\ Disclosures}

Human subjects: Consent was obtained by all participants in this study. Conflicts of interest: In compliance with the ICMJE uniform disclosure form, all authors declare the following:

Payment/services info: All authors have declared that no financial support was received from any organization for the submitted work. Financial relationships: All authors have declared that they have no financial relationships at present or within the previous three years with any organizations that might have an interest in the submitted work. Other relationships: All authors have declared that there are no other relationships or activities that could appear to have influenced the submitted work.

\section{References}

1. Poincloux L, Rouquette O, Abergel A: Endoscopic treatment of benign esophageal strictures: a literature review. Expert Rev Gastroenterol Hepatol. 2017, 11:53-64.

10.1080/17474124.2017.1260002

2. Rouphael C, Gordon IO, Thota PN: Lymphocytic esophagitis: still an enigma a decade later . World J Gastroenterol. 2017, 14:949-956. 10.3748/wjg.v23.i6.949

3. Genta RM: Lymphocytic esophagitis. Gastroenterol Hepatol. 2015, 11:559-561.

4. Haque S, Genta RM: Lymphocytic oesophagitis: clinicopathological aspects of an emerging condition. Gut. 2012, 61:1108-1114. 10.1136/gutjnl-2011-301014

5. Nguyen AD, Dunbar KB: How to approach lymphocytic esophagitis. Curr Gastroenterol Rep. 2017, 19:24. 10.1007/s11894-017-0564-y 